\title{
Genesis of the BIF-hosted high-grade ores in the North China Craton
}

\author{
Hou-MIN LI AND LI-XING LI
}

MNR Key Laboratory of Metallogeny and Mineral Assessment, Institute of Mineral Resources, Chinese Academy of Geological Sciences, Beijing 100037, China (lihoumin2002@163.com)

Iron ore deposits formed through upgrading of Precambrian banded iron formations (BIFs) are the primary sources of iron in the world. Most of them are high-grade hematite deposits, while high-grade magnetite ores are less common. In the North China Craton where NeoarcheanPaleoproterozoic BIFs are abundant, economic high-grade hematite ores are scarce, but high-grade magnetite ores are widely developed. Recent dating results indicate that the high-grade magnetite mineralization of the Gongchangling formed at $1.86 \mathrm{Ga}$, significantly later than $\sim 2.55 \mathrm{Ga}$ BIF deposition. The BIF-hosted high-grade magnetite mineralization shares genetic similarities with high-grade hematite mineralization but records higher ore-forming temperatures than the latter, likely reflecting a greater depth of the magnetite mineralization. The dating results of the Yuanjiacun reveal that high-grade hematite mineralization formed at $1.41 \mathrm{Ga}$ and $1.34 \mathrm{Ga}$, obviously later than Paleoproterozoic BIF deposition. The high-grade hematite ores are considered to have resulted from ingress of hypogene hydrothermal fluid, similar to high-grade hematite mineralization worldwide. However, most of the high-grade ores in the North China Craton were removed by extensive erosion during later regional uplift events. 